\title{
Introducing a holistic approach to model and link fouling resistances
}

\author{
Florian Schlüter ${ }^{1} \cdot$ Wolfgang Augustin $^{1}$ (D) $\cdot$ Stephan Scholl ${ }^{1}$
}

Received: 8 November 2019 / Accepted: 5 December 2020 / Published online: 21 December 2020

(C) The Author(s) 2020

\begin{abstract}
Fouling is the unwanted deposition of soils on heat transfer surfaces and is a major challenge for industry and has been s subject to scientific investigations for decades, still being an unsolved problem for many applications. A fouling situation is commonly quantified with the thermal fouling resistance describing the integral fouling behavior of an apparatus. Modeling of this quantity is a permanent subject to research. This contribution presents the basics of an expanded consideration by introducing a holistic approach to model and link fouling resistances based on the extension of previous work in this field. A thermal and a mass based approach to calculate fouling resistances are considered integrally and locally. This will provide a detailed knowledge of the fouling behavior. Various variables are needed for modeling the different fouling resistances. Therefore, both experimental and analytical methods have to be applied to obtain the required data regarding local differences of crystallization deposits within double-pipe heat exchangers. Here the planned experimental and analytical approaches to receive all the required input data are described, also presenting the required test equipment briefly. Core equipment is a test rig equipped with double pipe heat exchangers, which allows the measurement of thermal and fluid flow related values and provides samples for the analysis of the fouling deposits. Furthermore, the aim of the new modeling concept is to link integral and local fouling resistances by taking into account locally varying parameters regarding the fouling layer. In order to allow for that, a recalculation of the thermal fouling resistance into a corrected version by considering heat transfer enhancing effects attempts to correlate with the mass based approach in a first step. In the end, the holistic modelling approach is presented.
\end{abstract}

\section{List of symbols}

A Heat transfer surface, $\mathrm{m}^{2}$

d Tube diameter, $m$

$\mathrm{k} \quad$ Overall heat transfer coefficient, $\mathrm{W} \mathrm{m}^{-2} \mathrm{~K}^{-1}$

$\mathrm{k}_{\mathrm{s}} \quad$ Roughness height, $\mathrm{m}$

$\mathrm{k}^{+} \quad$ Roughness parameter, -

1 Local position, $m$

$\mathrm{L}$ Tube length, $\mathrm{m}$

$\mathrm{m}_{\mathrm{f}} \quad$ Fouling mass per unit area, $\mathrm{kg} \mathrm{m}^{-2}$

$\mathrm{Nu}$ Nusselt number, -

$\mathrm{p}$ Pressure, $\mathrm{Pa}$

Pr Prandtl number, -

$\mathrm{r}$ Tube radius, $\mathrm{m}$

Re Reynolds number, -

$\mathrm{R}_{\mathrm{f}} \quad$ Fouling resistance, $\mathrm{m}^{2} \mathrm{~K} \mathrm{~W}^{-1}$

$\mathrm{t}$ Time, $\mathrm{s}$

Wolfgang Augustin

w.augustin@tu-braunschweig.de

1 Institute for Chemical and Thermal Process Engineering, Technische Universität Braunschweig, Langer Kamp 7,

38106 Braunschweig, Germany

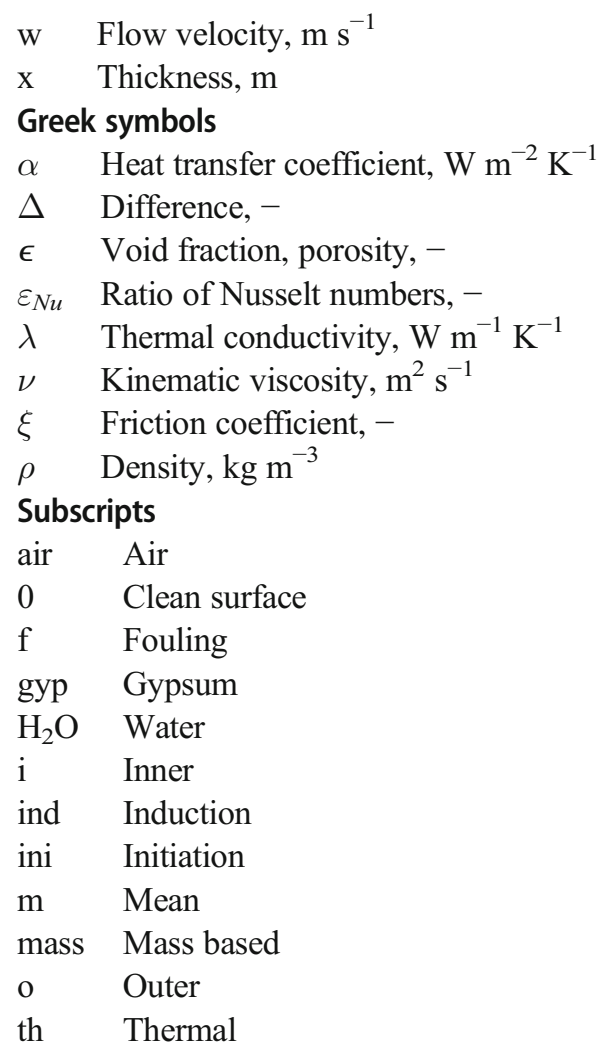




$\begin{array}{ll}\text { w } & \text { Tube wall } \\ \xi & \text { Friction } \\ \omega & \text { Acceleration }\end{array}$

\section{Introduction}

Fouling on heat exchanger surfaces is a severe issue in the chemical and process industry. Negative effects comprise of higher energy costs, additional investment for the oversizing of apparatus, down times for cleaning and accelerated corrosion $[1,2]$. Therefore, fouling has been a subject for scientific investigations for decades [3] and was already described as the major unresolved problem in heat transfer [4]. A fundamental approach to model the fouling process was introduced in the 1950s by Kern and Seaton [5] which was the basis for most of the fouling models developed afterwards [3].

One of the most rife deposition mechanism is crystallization fouling. In general, this fouling process can be divided into nucleation, growth, adhesion, removal and aging [6]. Figure 1 shows the three consecutive phases which typically occur when evaluating the time-dependent fouling behavior: i) the initiation phase, ii) the roughness controlled phase and iii) the crystal growth phase [7]. The first two make up for the induction phase. In this phase first crystals are formed on the surface, but initially with no influence on heat transfer. With increasing crystal size and coverage of the heat transfer surface the surface roughness due to the deposit leads to an enhanced heat transfer resulting in an apparent negative thermal fouling resistance. The roughness effect remains constant from this point on while the single crystal clusters cross-link and a dense bottom layer with increasing thickness is formed and deteriorates heat transfer noticeably [8]. This negative effect is superimposed by the co-occurring enhancement of the fouling-sided heat transfer. Particularly with regard to the

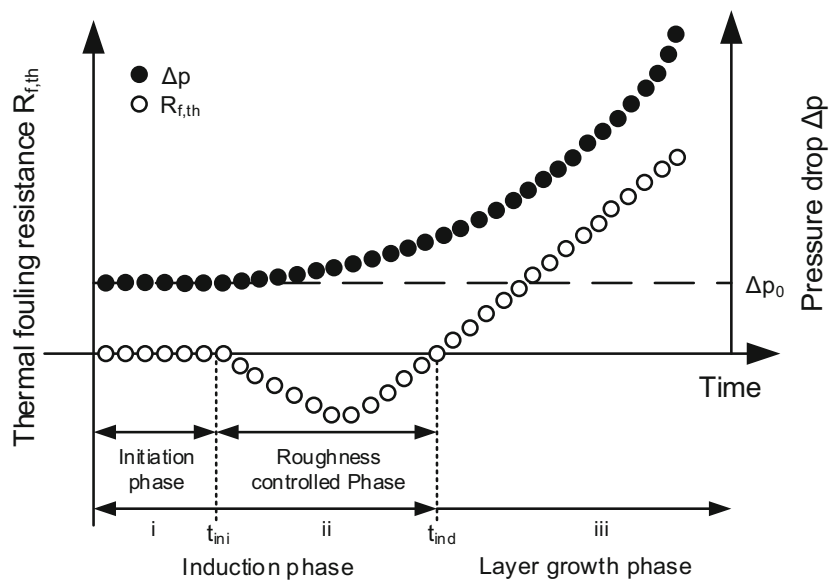

Fig. 1 Schematic development of the thermal fouling resistance and the pressure drop over process time; adapted from [7] fouling deposition in tubes this is attributed to two effects: (i) the roughness and (ii) the constriction of the flow crosssection with the resulting acceleration of flow [8]. On the other hand roughness and constriction result in an increased pressure drop, already appearing in the induction phase, see Fig. 1. These imposing trends require a distinction of the term fouling resistance into a thermal and a mass based fouling resistance. The inlet and outlet temperatures of a heat exchanger determine the integral thermal fouling resistance $R_{f, t h \text {, int }}$ while the pressure drop determines the hydraulic behavior and the integral mass based fouling resistance $R_{f, \text { mass, int }}$ [7].

Both, in the design phase of a new heat exchanger as well as for the assessment of an equipment in a fouling service, fouling behavior is typically regarded as an integral phenomena, e.g. considering the heat balance or pressure drop of an apparatus. Local phenomena as the uneven distribution of fouling deposits inside a heat exchanger are rarely described in literature and are usually not taken into account for modeling [8-12]. However, local differences found by optical inspection at different axial positions of a fouled heat exchanger tube indicate a considerable influence on the heat exchanger performance, see Fig. 2 [12]. The commonly used integral thermal fouling resistance is based on the heat exchanger's heat balance and therefore not able to reveal such local differences [9].

Experimental investigations of local thermal fouling resistances of $\mathrm{CaSO}_{4}$ deposits inside a double-pipe heat exchanger were presented by Goedecke et al. [9] and Albert [13]. Both found, that the integral assessment of the fouling process is not suitable to detect local processes or to identify the proceeding sub-processes and their interactions and to explain the determining mechanisms. Therefore, both a local and a timeresolved acquisition, analysis and modeling is essential for a deeper insight into the fouling process.

Figure 3 shows the core structure of the new holistic modeling concept. A distinction is made between three types of fouling resistances: (i) the thermal, (ii) the corrected and (iii) the mass based fouling resistance. All fouling resistances are considered by an integral and a local approach. A direct correlation between local thermal fouling resistances, based on local temperature measurements, and the integral thermal fouling resistance, based on the integral heat balance, is not possible [9]. Therefore, they are linked by a crossed arrow. Furthermore, thermal fouling resistances cannot be correlated directly with mass based fouling resistances. Yeap et al. [14] investigated the link between the thermal and hydraulic behavior of a heat exchanger subjected to crude oil fouling and outlined that the relationship is not straightforward if roughness and tube constriction need to be considered. Albert et al. [8] developed a model to correct the integral thermal fouling resistance by taking roughness and constriction effects on heat transfer into account. The resulting corrected fouling resistance provides the connecting link between thermal and mass based fouling resistances. To calculate corrected local fouling 


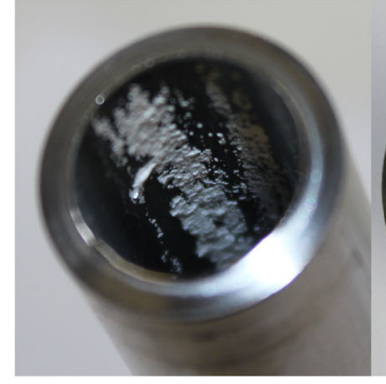

$500 \mathrm{~mm}$

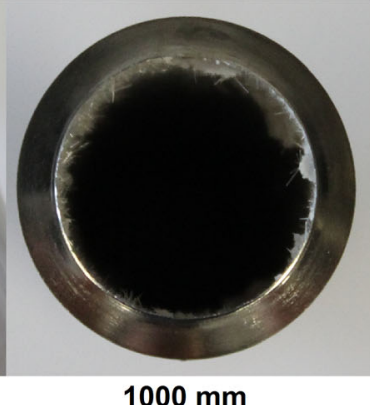

$1000 \mathrm{~mm}$

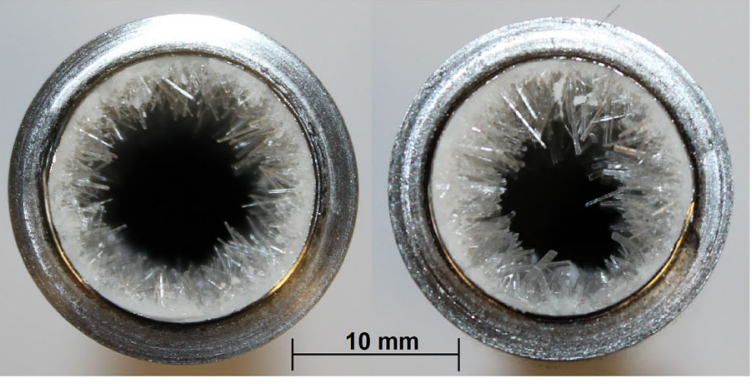

$1750 \mathrm{~mm}$
$2000 \mathrm{~mm}$

Fig. 2 Photographs of different tube cross-sections after cutting a heat exchanger tube with crystallization fouling $\left(\mathrm{CaSO}_{4}\right)$ inside; adapted from [12]

resistances this model will be extended and integrated into a local consideration, see Fig. 3. A similar detailed modeling approach considering the impact of roughness and aging on the thermal fouling related to crude oil fouling was presented by Coletti et al. [15].

In order to provide better understanding of the methodology and the interrelations within the new modeling concept section 2 describes the fundamental model equations. In addition, the derivation of these equations is described briefly including the assumptions made for their application. This represents the basis of the approach which is presented entirely in section 3.1. Completing the overall picture of the new approach, the procedural methods to generate and provide the input data required for modeling are presented in section 3.2.

\section{Mathematical basics of the model}

A general mathematical description of the thermal and the mass based fouling resistance is given in this section. The key parts of the fouling model to consider topographic and constriction effects on heat transfer which was developed by Albert et al. [8] to provide corrected fouling resistances are presented afterwards. In addition, the procedure to calculate material/physical properties of the deposit which affect the mass based fouling resistance is described.

\subsection{Fouling resistances}

Basically, fouling can be quantified by two different approaches to describe the fouling resistance: the thermal and the mass based fouling resistance [16]. The thermal fouling resistance quantifies the change in heat transfer due to a growing fouling layer and is formed by the difference of the overall heat transfer coefficients with a fouled $\left(k_{f}\right)$ and a clean $\left(k_{0}\right)$ heat transfer surface. Often fouling occurs only on one side of the heat transferring wall of a heat exchanger, which allows to describe $R_{f, \text { th }}$ for flat surfaces and thin-walled tubes $\left(r_{0} / k_{i} \approx 1\right)$ by

$R_{f, t h}=\frac{1}{k_{f}}-\frac{1}{k_{0}}$.

Please note, Eq. (1) does not consider occurring changes of the fouling-sided film heat transfer coefficient due to the surface roughness of the fouling layer and the constriction of the flow cross-section.

Assuming a fouling layer with the thickness $x_{f}$ is uniformly distributed over the heat transfer surface and has a constant density $\rho_{f}$ and thermal conductivity $\lambda_{f}$, the mass based heat transfer resistance of the fouling layer is given by

$R_{f, \text { mass }}=\frac{x_{f}}{\lambda_{f}}=\frac{m_{f}}{\rho_{f} \lambda_{f}}$

with the deposited solid mass per unit area

$m_{f}=\rho_{f} x_{f}$.

In contrast to Eq. (1) roughness and constriction have no influence and mass based fouling resistances are always positive. Instead, a homogeneously formed fouling layer all over the heat transfer surface is implied, which rarely occurs in practice [14].
Fig. 3 Core structure of a new holistic approach to model and link different fouling resistances determined with a thermal and a mass based approach

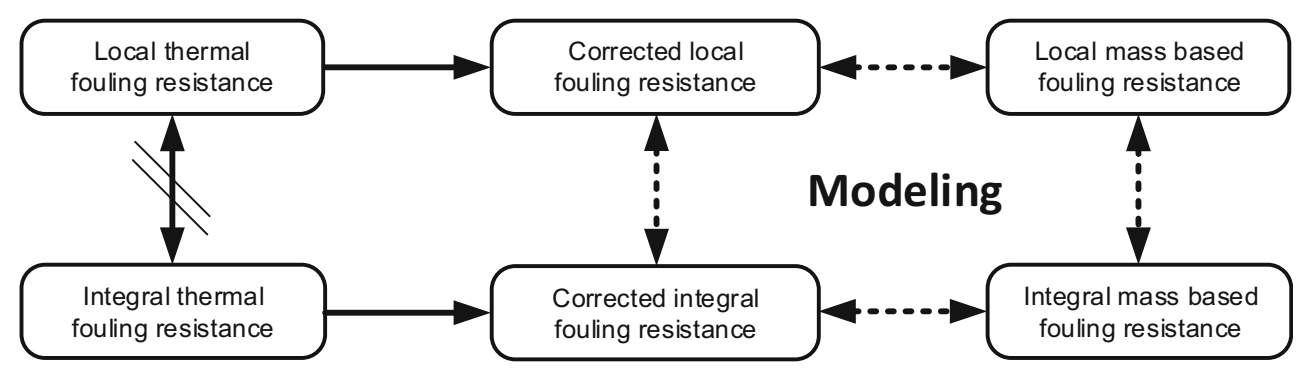




\subsection{Topographic effects on heat transfer}

The influence of rough surfaces on heat and mass transfer has been a subject of intense research activities in particular regarding the efficiency improvement of heat exchangers [17-21]. The roughness effect on heat transfer is determined by shape, size and orientation of the roughness elements and on their distribution over a heat transfer surface [21]. Furthermore, the roughness effects of different fouling types are partially described in literature $[8,15,22,23]$. However, a general characterization of the surface structure in case of a crystalline fouling layer, i.e. in terms of roughness parameters, is not existing [23]. For determining the influences of crystallization fouling on heat transfer Albert et al. [8] carried out experimental and theoretical investigations. Fouling experiments were conducted with a test rig equipped with two double-pipe heat exchangers operated in countercurrent flow with calcium sulphate fouling inside the inner tubes. Results showed that the change of the topography at the interphase crystal layer/salt solution, respectively heat exchanger surface/salt solution, affects the fluid dynamic as well as the heat transfer behavior. The turbulence enhancement at the boundary layer increases the heat transfer coefficient $\alpha_{i}$. This is usually neglected in calculations of the fouling resistance $R_{f, t h}$. Therefore, a model was developed for taking these effects into account when quantifying the thermal fouling behavior [8]. The model equations are presented here in short.

The overall heat transfer coefficient through a tube wall with fouling on the inside in case of thin layers $\left(A_{i, f} \approx A_{i}\right)$ is given by

$\frac{1}{k_{f}}=\left(\frac{A}{\alpha_{i} A_{i}}+\frac{x_{w} A}{\lambda_{w} A_{m}}+\frac{A}{\alpha_{o} A_{o}}\right)_{t=0 s}+R_{f, t h}(t)$ with $\quad R_{f}(t)=\frac{x_{i, f} A}{\lambda_{i, f} A_{i}}$

Equation (4) shows that any increase of the heat transfer coefficient $\alpha_{i}$ leads to a compensation of the thermal fouling resistance $R_{f, t h}$. To consider this change in heat transfer separately, Eq. (4) can be transformed to

$\frac{1}{k_{f}}=\frac{A}{\alpha_{i}(t) A_{i}}+R_{f, t h}(t)+\frac{1}{k_{0}^{\prime}} ;$ with $\frac{1}{k_{0}^{\prime}}=\frac{x_{w} A}{\lambda_{w} A_{m}}+\frac{A}{\alpha_{o} A_{o}}$.

Assuming that only the surface roughness due to deposition causes a change of the heat transfer coefficient $\alpha_{i}(t)$, the friction coefficient $\xi_{f}(t)$ is used to characterize the roughness and to describe the heat transfer enhancement and is determined by the change of flow resistance [8]:

$\alpha_{i}(t) \propto \frac{\xi_{f}(t)}{\xi_{0}} \alpha_{i, 0} ;$ or $\quad N u \propto \frac{\xi_{f}(t)}{\xi_{0}} N u_{0}$

The index " 0 " relates to the clean condition of the heat transfer surface at $t=0 \mathrm{~s}$. Combining Eqs. (5) and (6) results in a new fouling model. The dependency of heat transfer from flow resistance $\xi_{f}$ is considered by the term $\varepsilon_{N u, \xi}=N u / N u_{0}$ in order to take heat transfer enhancement due to fouling into account:

$R_{f, t h}(t, \xi)=\frac{1}{k_{f}}-\frac{A}{\left(\alpha_{i, 0} \varepsilon_{N u, \xi}\right) A_{i}}-\left(\frac{x_{w} A}{\lambda_{w} A_{m}}+\frac{A}{\alpha_{o} A_{o}}\right)$

Albert et al. [8] applied four different heat transfer correlations from Nunner [24], Burck [25], Hughmark [26] and Ceylan and Kelbaliyev [27] in his fouling model to account for the increase in heat transfer on rough surfaces at turbulent flow.

\subsection{Constriction effects on heat transfer}

With increasing deposition a compact crystal layer builds up on the heat transfer surface. The roughness effects persist and the fouling layer reduces the free flow cross-section. Accordingly, the fluid flow is accelerated which increases the turbulence and the heat transfer likewise. This effect was also investigated by Albert et al. [8].

Figure 4 shows the assumption of a linear fouling layer built up from inlet to outlet of a heat exchanger tube. If the volumetric flow rate remains constant the flow accelerates in accordance with the increasing constriction of the crosssection along the tube. Hence, the flow turbulence and the effect on heat transfer varies depending on the local position.

In order to consider the dependency of heat transfer from the constriction at different local positions the well-known approach of Gnielinski for turbulent pipe flow is used [28, 29]:

$N u_{\omega}=\frac{(\xi / 8) \operatorname{Re} \operatorname{Pr}}{1+12.7 \sqrt{\xi / 8}\left(\operatorname{Pr}^{2 / 3}-1\right)}\left[1+\frac{1}{3}\left(\frac{d_{i, f}}{l}\right)^{2 / 3}\right]$

with

$\xi=\left(1.8 \log _{10} R e^{-1.5}\right)^{-2}$ and $R e=\frac{w_{l} d_{i, f}}{\nu}$

Here $d_{i, f}$ is the diameter of the constricted cross-section, $l$ is the corresponding local position and $w_{l}$ is the flow velocity which results from the constriction at that local position. Albert et al. [8] used the idealized deposit distribution according to Fig. 4 with knowing the constriction at the tube outlet to calculate an integral averaged value of the increased Nusselt number. More precise local results can be obtained if the exact axial distribution of the fouling layer is known. Subsequently, the improvement of heat transfer is defined by the ratio of the Nusselt numbers with flow acceleration $N u_{\omega}$ and without constriction $N u_{0}$ :

$\varepsilon_{N u, \omega}=\frac{N u_{\omega}}{N u_{0}}$ 
Fig. 4 Idealized distribution of deposits along the inner tube of a double-pipe heat exchanger operating in counterflow; adapted from [8]

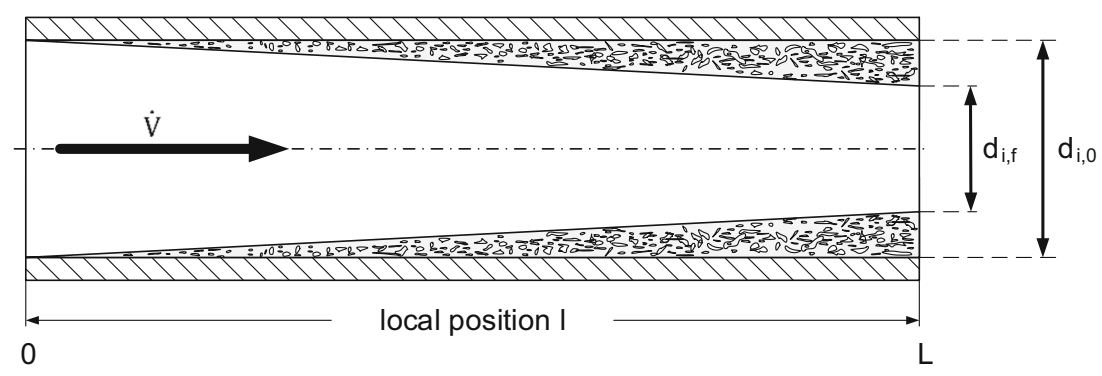

$N u_{0}$ is calculated in accordance with Eqs. (8) and (9) by applying the original tube diameter $d_{i, 0}$ and the corresponding flow velocity $w_{0}$.

\subsubsection{Combination of roughness and constriction effects}

Substitution of Eqs. (8) to (10) into Eq. (7) yields a fouling model which considers both roughness and constriction effects on heat transfer [8].

$R_{f}(t, \xi)=\frac{1}{k_{f}}-\frac{A}{\left(\alpha_{i, 0} \varepsilon_{N u, \xi} \varepsilon_{N u, \omega}\right) A_{i}}-\left(\frac{x_{w} A}{\lambda_{w} A_{m}}+\frac{A}{\alpha_{o} A_{o}}\right)$

By applying the different heat transfer correlations of Nunner [24], Burck [25], Hughmark [26] and Ceylan and Kelbaliyev [27] corrected integral fouling resistances were calculated and compared to fouling resistances based on the assumption of a constant heat transfer [8]. It was shown that the approaches of Nunner [24] and Hughmark [26] are the most promising ones for considering roughness and constriction effects on integral heat transfer, presented in Fig. 5. Hence, these correlations will be used when adapting Eq. (11) to calculate corrected local fouling resistances.

\subsection{Structural properties of the deposit}

The internal structure of the fouling deposit affects the heat flux within the layer and determines the mass based fouling resistance, see Eq. (2). The structure depends on the fluid dynamic conditions, e.g. with increasing Reynolds number the calcium sulfate layer becomes denser and the crystal size decreases [30]. Furthermore, the interdependent material properties porosity $\epsilon$, density $\rho_{f}$ and thermal conductivity $\lambda_{f}$ are essential to determine the mass based fouling resistance, see Eq. (2). In accordance with Brahim [31] the thermal conductivity of $\mathrm{CaSO}_{4}$ deposits is calculated by averaging two alternative approaches. The solid matrix and the void (porosity) of the fouling layer can be considered as resistances in series, see Eq. (13), or as resistances in parallel, see Eq. (14) [32]. Therefore, the thermal conductivity of water $\lambda_{\mathrm{H}_{2} \mathrm{O}}$ and gypsum $\left(\mathrm{CaSO}_{4} \cdot 2 \mathrm{H}_{2} \mathrm{O}\right) \lambda_{\text {gyp }}$ is used.

$$
\begin{aligned}
& \lambda_{f}=\frac{\lambda_{f, I}+\lambda_{f, I I}}{2} \\
& \lambda_{f, I}=\epsilon \cdot \lambda_{H_{2} O}+(1-\epsilon) \cdot \lambda_{g y p} \\
& \frac{1}{\lambda_{f, I I}}=\frac{\epsilon}{\lambda_{H_{2} O}}+\frac{1-\epsilon}{\lambda_{g y p}}
\end{aligned}
$$

Fig. 5 Corrected fouling resistances by using the heat transfer correlations of Nunner and Hughmark in comparison to the integral thermal fouling resistance with constant heat transfer; adapted from [8]

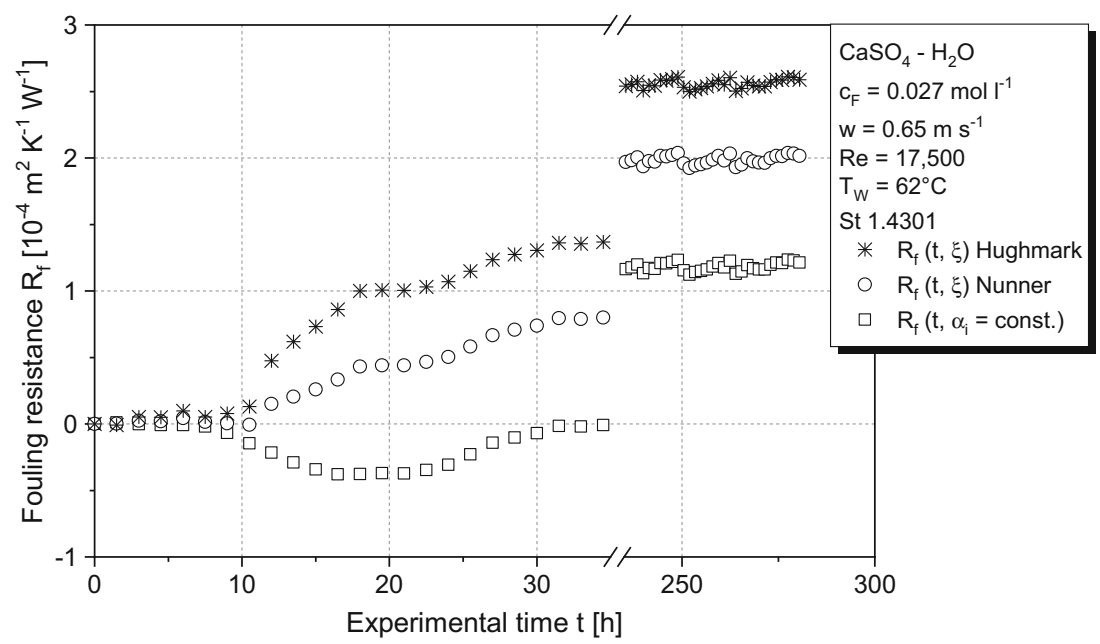


A mean value for the thermal conductivity of $1.2 \mathrm{~W} \mathrm{~m}^{-1} \mathrm{~K}^{-1}$ was determined for $\mathrm{a} \mathrm{CaSO}_{4}$ fouling layer produced in an electrically heated flow channel, see Fig. 6 [33]. This value results from a mean layer porosity of $10 \%$ and the thermal conductivity of pure gypsum $\left(\lambda_{g y p}=1.3 \mathrm{~W} \mathrm{~m}^{-1} \mathrm{~K}^{-1}\right)$ [34].

Furthermore, Fig. 6 shows that four different sublayers were identified, which differ in structure, color and hardness. Therefore, material properties of the layer depend on the local radial position within the fouling layer as well as on the total layer thickness. An increasing total layer thickness leads to an increase of the density in the sublayers near the heat transfer wall. [31, 35]

In accordance with Eqs. (15) and (16) the density of a fouling layer is also directly related to the porosity and is calculated with the assumption of air or water within the void fraction:

$$
\begin{aligned}
& \rho_{f}=\epsilon \cdot \rho_{\text {air }}+(1-\epsilon) \cdot \rho_{g y p} \\
& \rho_{f}=\epsilon \cdot \rho_{H_{2} O}+(1-\epsilon) \cdot \rho_{g y p}
\end{aligned}
$$

With the density of pure gypsum $\left(\rho_{\text {gyp }}=2320 \mathrm{~kg} \mathrm{~m}^{-3}\right)$ and a mean porosity of around $50 \%$ Hirsch [35] calculated mean densities of $\rho_{f}=1100 \mathrm{~kg} \mathrm{~m}^{-3}$ for dry $\mathrm{CaSO}_{4}$ layers and around $\rho_{f}=1600 \mathrm{~kg} \mathrm{~m}^{-3}$ for moisture deposits.

\section{Composition of the new holistic approach}

The combination of different fouling models shall serve a holistic description of the fouling behavior by taking into account local variations and hence give the opportunity to predict fouling deposition precisely. This approach is developed on the basis of investigations with $\mathrm{CaSO}_{4}$ crystallization fouling.

The basic structure of the new approach was introduced in Fig. 3. Figure 7 shows the entire composition of the modeling concept and gives an overview of all required parameters to model the participating fouling resistances. Measured variables are displayed in rectangles and provided by applying different experimental methods. Calculated variables are displayed in rectangles with rounded corners and are determined by using existing calculation procedures. Filled arrows indicate a direct dependency between fouling resistances. Dotted arrows indicate the missing correlation between fouling resistances. The analytical approach of the model is presented in the following. All experimental methods to provide the required variables are described afterwards.

\subsection{Analytical approach}

The holistic model aims to link corrected with mass based fouling resistances as well as integral and local fouling resistances, see Fig. 7. The fouling resistances are based on different approaches by using various variables as input data and are described shortly in the following:

1. The integral thermal fouling resistance results from the temporal change of the integral heat transfer using Eq. (1). Therefore, inlet and outlet temperatures of a heat exchanger need to be measured.

2. According to Eq. (3) the integral mass based fouling resistance is determined by mean values of the deposit's thickness, mass, density and thermal conductivity.

3. The corrected integral fouling resistance is calculated with the model of Albert et al. [8] based on the integral thermal fouling resistance, see Eq. (11). The mean layer thickness, the mean flow velocity and the integral friction coefficient are used.

4. In order to determine local thermal fouling resistances local temperatures measured at the wall and in the heating medium are used to quantify local overall heat transfer coefficients. The calculation process was presented by Schlüter et al. [12].

5. The calculation of local mass based fouling resistances is carried out by applying a local consideration of Eq. (3). Accordingly, the local material properties density and thermal conductivity are required, which are calculated
Fig. 6 Profile of $\mathrm{CaSO}_{4}$ fouling layer produced in an electrically heated flow channel; adapted from [33]

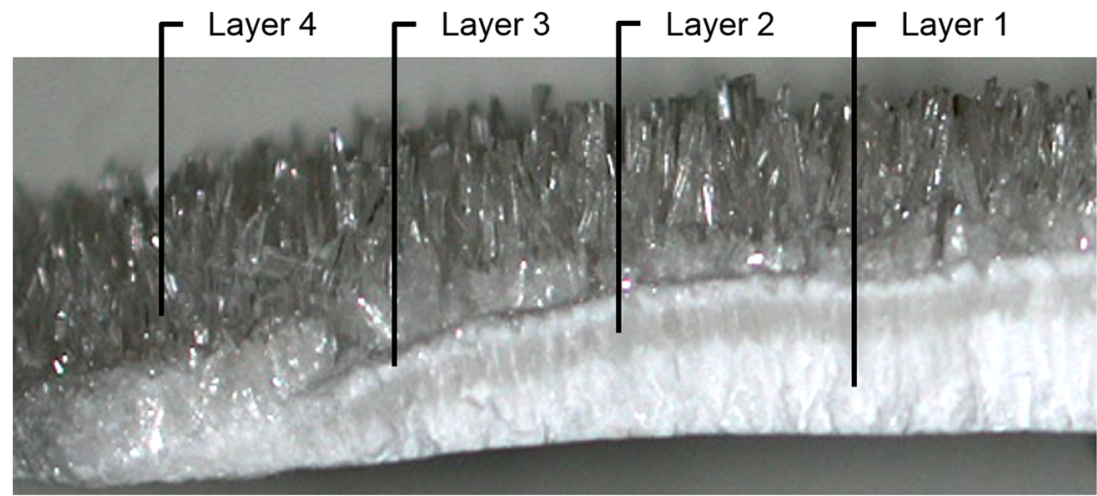




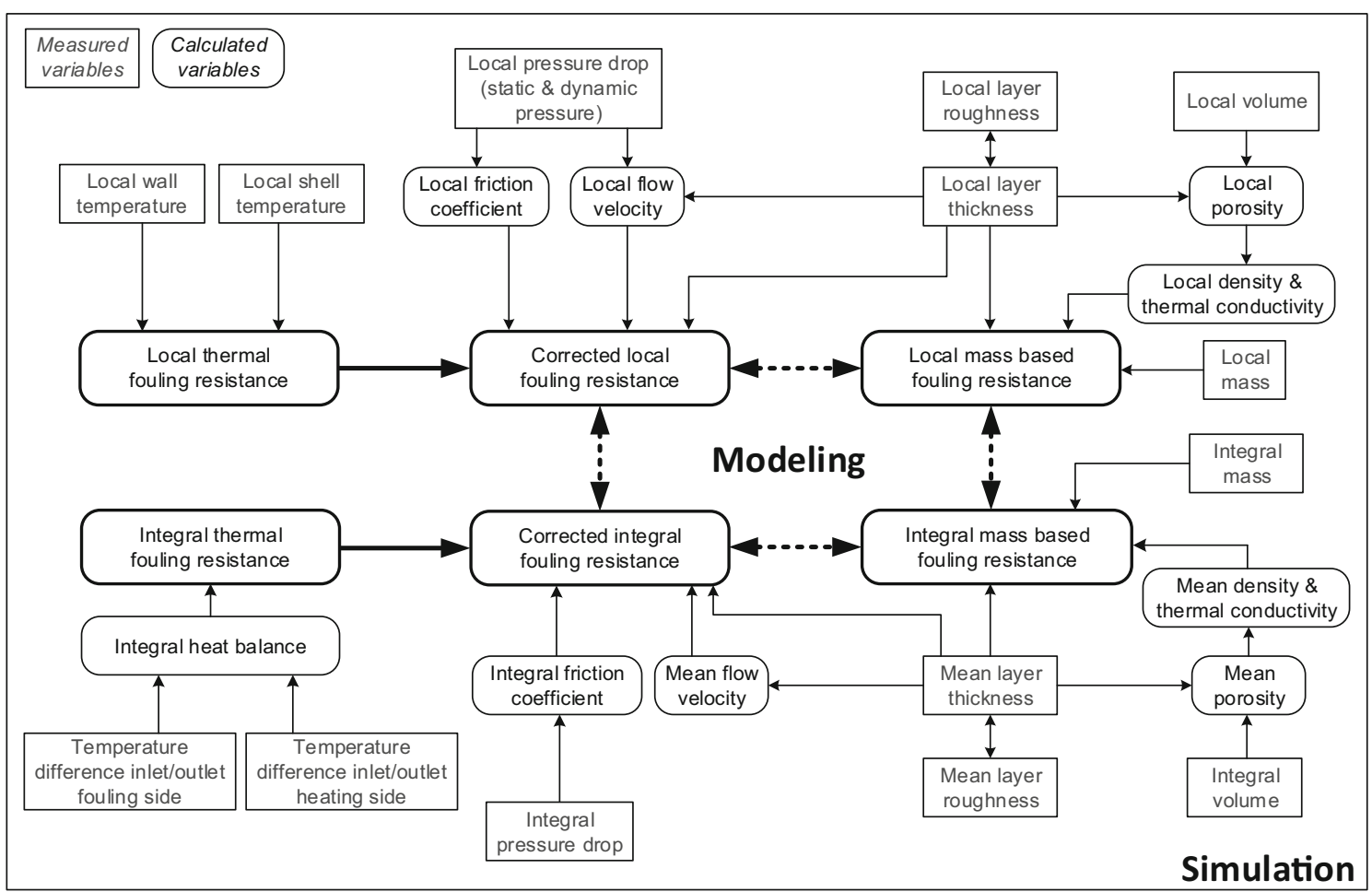

Fig. 7 Structure of the new modeling concept with measured and calculated variables

with Eqs. (12) to (15). Furthermore the local layer thickness and/or the local fouling mass is required. This variables result from experiments, see section 3.2.

6. The corrected local fouling resistance is based on the local thermal fouling resistance and determined in accordance with Eq. (11), but here with a local consideration. Therefore, the local constriction due to the layer thickness, the local flow velocity and the local friction coefficient are used.

After the calculation procedure the corrected and mass based fouling resistances can be correlated. The experimental data from investigations with calcium sulfate and subsequently calcium carbonate will be integrated in a simulation for validating the holistic model in case of the most typical fouling crystallization products in cooling water applications. In longer term the universal applicability of the model regarding other fouling types needs to be examined. In general, the fundamental influencing factors deposition mass, layer thickness and layer structure like compactness and roughness as well as the resulting heat transfer will vary for each fouling type but have the same significance for modeling.

\subsection{Experimental methods}

This section presents a short description of the fouling test rig to produce crystalline deposits as well as all additional experimental methods to provide input data for modeling the different fouling resistances. The following description is segmented with regard to the square boxes in Fig. 7. First experimental results by applying these methods with $\mathrm{CaSO}_{4}$ fouling was presented by Schlüter et al. [12].

\subsubsection{Integral heat balance and pressure drop}

Figure 8 shows the test rig which is used for fouling experiments [12]. The core components of the experimental setup are two identical double-pipe heat exchangers made of stainless steel (HX1 and HX2) with inner tube dimensions of $20 \times 2 \times 2000 \mathrm{~mm}$. An aqueous salt solution flows on the tube side of both test sections and hot water passes through the shell side in counterflow. Hence, crystallization fouling is produced on the tube side. A plate and frame heat exchanger (HX3) in conjunction with an automatic valve control the heat exchanger inlet temperatures of the salt solution using cooling water from an on-site water circuit. Shell side and tube side inlet and outlet temperatures of both test sections are measured with type $\mathrm{K}$ thermocouples determining the integral heat balance and are used to calculate integral thermal fouling resistances, see Eq. (1). In addition, differential pressure transducers measure the integral pressure drop of both heat exchangers to monitor the integral fouling behavior. 


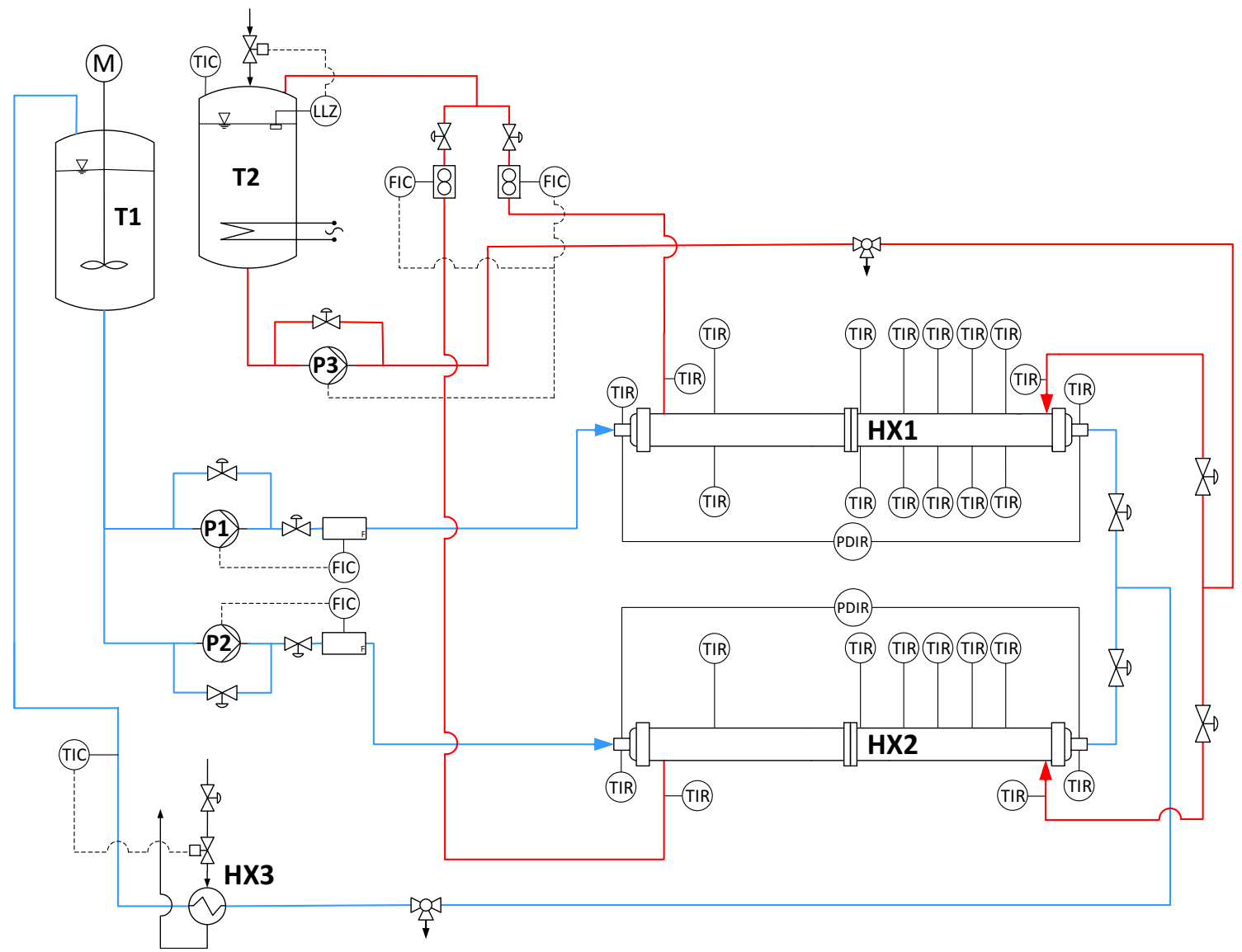

Fig. 8 Process flow diagram of the fouling test rig equipped with two double-pipe heat exchangers (HX1, HX2), a heating circuit and a product circuit (FIC: inductive flow meters; LLZ: level sensor; M: motor; P: pumps; T: tanks; TIC/TIR: thermocouples)

\subsubsection{Local shell side and local wall temperatures}

Heat exchanger HX1 is equipped with six thermocouples (TIR) at different axial positions on the shell side and along the wall of the inner tube for local temperature measurements and the determination of the local heat transfer. In addition to the shell side thermocouples heat exchanger HX2 is equipped with a fiber optic sensor to determine local temperatures along the wall of the inner heat exchanger tube, see Fig. 9. The thermocouples are installed in the depicted manner to allow for a high axial resolution of temperature measurements towards the hot end of the heat exchanger where most deposition takes place. The fiber-based measurement system features an active monitoring unit which is connected to the passive sensor fiber (Luna, ODiSI A50). The monitoring unit transmits light into the fiber from a broadband source. Characteristics of the light traveling within the fiber are modified as a function of temperature. These changes are detected in the backscattered light which is later collected by the monitoring unit, analyzed and then converted into temperature data. This technique provides a higher resolution of the axial temperature profile and a more precise description of the local
Fig. 9 Schematic layout of test section HX2 with an arrangement of six local thermocouples along the annular clearance between tube and shell and the fiber sensor in the tube wall

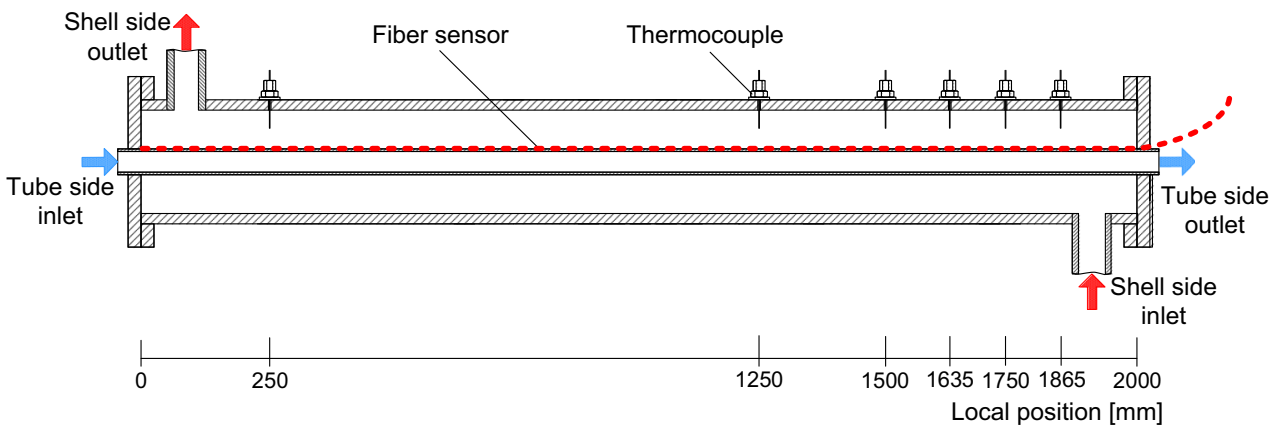




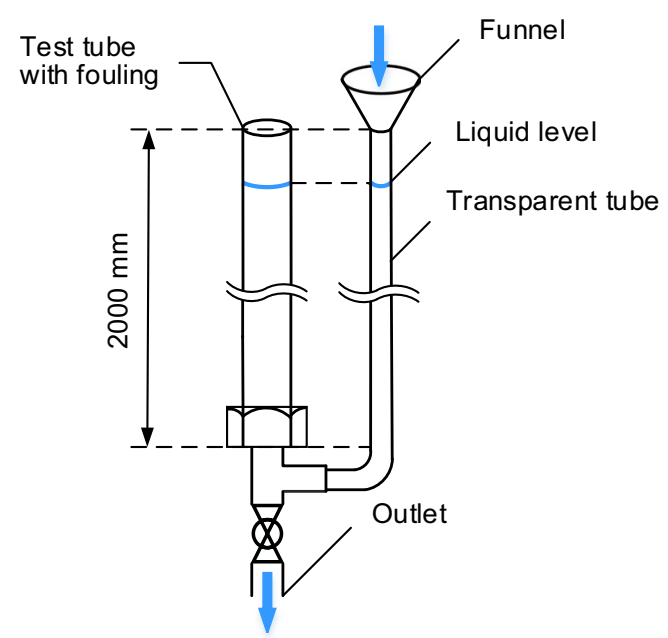

Fig. 10 Schematic setup of the measuring procedure to determine the volume of fouling deposits inside a heat exchanger tube

fouling behavior compared to the usage of thermocouples only. The sensor is inserted in a notch of $1 \mathrm{~mm}$ depth in the tube wall. Along the fiber sensor temperature variations can be detected with an axial resolution up to $10 \mathrm{~mm}$. Since the application of this measuring technique is a novel approach for local fouling investigations, heat exchanger HX1 serves as validation for the measurements. The calculation of local thermal fouling resistances on the basis of local temperatures is described by Schlüter et al. [12].

Besides the thermal investigations various other methods provide essential data for modeling the corrected and mass based fouling resistances according to Fig. 7. The methods to determine the measured variables are described briefly in the following.

\subsubsection{Fouling layer volume, thickness, roughness and mass}

To investigate the axial distribution of the tube side deposit regarding its volume, mass, thickness and roughness the fouled heat exchanger tube is dismounted after a fouling experiment. Figure 10 shows an experimental setup designed to examine the volume of the deposit by applying the principle of communicating tubes. Water is filled incrementally over a funnel into a translucent tube and the fouled test tube. Liquid levels are noted and compared with the liquid levels obtained by using a clean test tube after adding the same volume of water. Hence, the water displaced by the deposit inside the tube is determined locally and integrally along the heat exchanger tube. The measured volume of water corresponds to volume of the fouling layer.

Subsequent to the volumetric investigation, the fouled test tube is cut into ten segments of $200 \mathrm{~mm}$ length by using a tube cutter. Photographs of each cross-section of all segments are taken with a digital camera. The images are analyzed with a suitable image analysis software (ImageJ, Wayne Rasband, $\mathrm{NIH})$ to determine the thickness and roughness of a local fouling layer at each accessible axial position. The program can calculate the area of different circular shapes or freehand selections corresponding to layer thickness or roughness of the respective fouling deposit. With knowing the free tube area, thickness and roughness can be calculated. Subsequently, the porosity of a local deposit is determined by combining the results regarding the local volume and the local layer thickness. The thermal conductivity and density of the deposit are calculated in a next step according to Eqs. (12) and (16) with the assumption of water within the void. Finally, weighing the tube segments provides the axial distribution of the deposited mass per unit area.

\subsubsection{Local pressure drop measurement}

Local pressure drops have to be determined in order to calculate local friction coefficients, see Fig. 6. Inline measurements with pressure transducers inserted in the tube wall are not practical due to the crystalline deposit building up there.
Fig. 11 Assumed distribution of the crystal layer and the incremental pressure drops; adapted from [13]

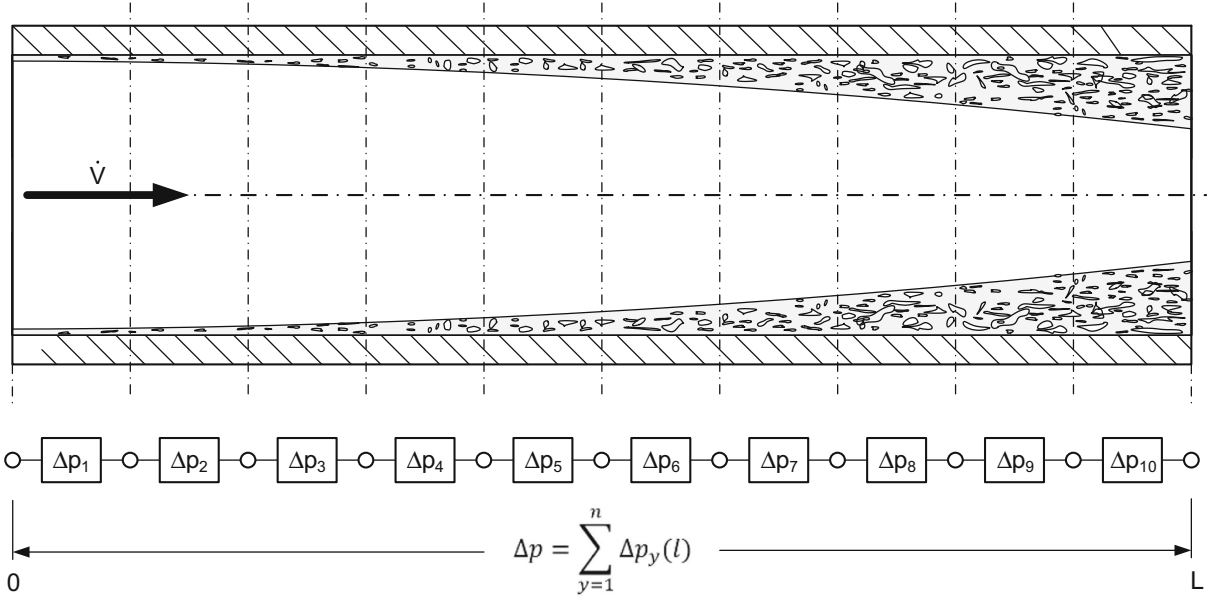


Hence, a new experimental setup equipped with a moveable Prandtl probe was developed and will be used to measure the pressure drop within the ten tube segments individually. Figure 11 shows that the measured pressure drops of the tube segments have to add up to the total pressure difference which is measured integrally with the inline differential pressure transducer of the fouling test rig, see Fig. 8. In addition, the Prandtl probe measures the dynamic pressure in each tube segment and thereby the increase of the local velocity due to the constriction can be calculated.

\section{Conclusion}

This work presents a new holistic approach to model and link fouling resistances as well as showing the planned experimental and analytical way to receive all the required input data. A distinction is made between six target values: thermal and mass based as well as corrected fouling resistances, all considered locally and integrally.

The integral values are determined by the conventional way of measuring the integral pressure drop and integral heat balance of the fouled heat exchanger tubes. More experimental and analytical effort is required for investigating local fouling resistances. For the thermal approach local thermocouples and a fiber sensor are applied to measure local temperatures and determine local overall heat transfer coefficients. More parameters like the local constriction, local mass as well as local material parameters, e.g. density and thermal conductivity, are used for modeling local mass based fouling resistances. A novel experimental layout will be used for measuring local pressure drops inside fouled tube segments with a Prandtl probe and determining local friction coefficients and local flow velocities which are needed for calculating the corrected local fouling resistances. After modeling the target values the link between the different fouling resistances will be investigated by taking all presented local parameters into account. A correlation between the different fouling resistances is essential for being able to simulate the fouling process entirely.

After validating the model with $\mathrm{CaSO}_{4}$ and $\mathrm{CaCO}_{3}$ deposits, which are the most typical crystallization products in cooling water applications, the universal applicability of the model regarding other types of fouling needs to be examined. Finally, the goal of modeling and simulation is to allow for extracting local fouling parameters only by having knowledge about the integral heat transfer and pressure drop behavior in combination.

With introducing the new modeling concept this contribution is the first part of an extensive work. Experimental results and first modeling results for comparison and validation will be shown in a following second paper which deals with the local part of the introduced holistic modeling concept.
Acknowledgements The authors would like to thank the German Research Foundation (DFG) for funding this project.

Funding Open Access funding enabled and organized by Projekt DEAL.

\section{Compliance with ethical standards}

Conflict of interest The authors declare that there is no conflict of interest.

Open Access This article is licensed under a Creative Commons Attribution 4.0 International License, which permits use, sharing, adaptation, distribution and reproduction in any medium or format, as long as you give appropriate credit to the original author(s) and the source, provide a link to the Creative Commons licence, and indicate if changes were made. The images or other third party material in this article are included in the article's Creative Commons licence, unless indicated otherwise in a credit line to the material. If material is not included in the article's Creative Commons licence and your intended use is not permitted by statutory regulation or exceeds the permitted use, you will need to obtain permission directly from the copyright holder. To view a copy of this licence, visit http://creativecommons.org/licenses/by/4.0/.

\section{References}

1. Epstein N (1983) Thinking about heat transfer fouling: a $5 \times 5$ matrix. Heat Transfer Eng 4:3-56

2. Steinhagen R, Müller-Steinhagen H, Maani K (1993) Problems and costs due to heat exchanger fouling in New Zealand industries. Heat Transfer Eng 14:19-30

3. Müller-Steinhagen H (2011) Heat transfer fouling: 50 years after the Kern and Seaton model. Heat Transfer Eng 32:1-13

4. Taborek J, Aoki T, Ritter RB, Palen JW, Knudsen JG (1972) Fouling - the major unresolved problem in heat transfer. Chem Eng Prog 68:59-67

5. Kern DQ, Seaton RA (1959) A theoretical analysis of thermal surface fouling. British Chem Eng 4:258-262

6. Bott TR (1995) Crystallisation and scale formation. In: Bott TR (ed) Fouling of heat exchangers, 1st edn. Elsevier, Amsterdam, pp 97 133

7. Schoenitz M, Grundemann L, Augustin W, Scholl S (2015) Fouling in microstructured devices: a review. Chem Commun 51:82138228

8. Albert F, Augustin W, Scholl S (2011) Roughness and constriction effects in crystallization fouling. Chem Eng Sci 66:499-509

9. Goedecke R, Drögemüller P, Augustin W, Scholl S (2016) Experiments on integral and local crystallization fouling resistances in a double-pipe heat exchanger with wire matrix inserts. Heat Transfer Eng 37:24-31

10. Fahiminia F, Watkinson AP, Epstein N (2007) Early events in the precipitation fouling of calcium sulphate dihydrate under sensible heating conditions. Can J Chem Eng 85:679-691

11. Mwaba MG, Rindt CCM, Van Steenhoven AA, Vorstman MAG (2006) Experimental investigation of $\mathrm{CaSO}_{4}$ crystallization on a flat plate. Heat Transfer Eng 27:42-54

12. Schlüter F, Schnöing L, Zettler H, Augustin W, Scholl S (2018) Measuring local crystallization fouling in a double-pipe heat exchanger. Heat Transfer Eng. https://doi.org/10.1080/01457632. 2018.1522084 
13. Albert F (2010) Grenzflächeneffekte bei der kristallinen Belagbildung auf wärmeübertragenden Flächen. Dissertation, Technische Universität Braunschweig

14. Yeap BL, Wilson DI, Polley GT, Pugh SJ (2004) Mitigation of crude oil refinery heat exchanger fouling through retrofits based on thermo-hydraulic fouling models. Chem Eng Res Des 82:53-71

15. Coletti F, Ishiyama EM, Paterson WR, Wilson DI, Macchietto S (2010) Impact of deposit aging and surface roughness on thermal fouling: distributed model. AICHE J 56:3257-3273

16. Schoenitz M, Finke JH, Melzig S, Hohlen A, Warmeling N, Müller-Goymann C, Augustin W, Scholl S (2015) Fouling in a micro heat exchanger during continuous crystallization of solid lipid nanoparticles. Heat Transfer Eng 36:731-740

17. Pohl W (1933) Einfluss der Wandrauigkeit auf den Wärmeübergang an Wasser. Forsch Ing-Wes 4:230-237

18. Sheriff N, Gumley P (1966) Heat-transfer and friction properties of surfaces with discrete roughnesses. Int J Heat Mass Transf 9:12971320

19. Feurstein G, Rampf H (1969) The influence of rectangular roughness on heat transfer and pressure drop in turbulent annular flow. Heat Mass Transf 2:19-30

20. Taylor RP, Hosni MH, Garner JW, Coleman HW (1992) Thermal boundary condition effects on heat transfer in turbulent rough-wall boundary layers. Heat Mass Transf 27:131-140

21. Mahato BK, Shemilt LW (1968) Effect of surface roughness on mass transfer. Chem Eng Sci 23:183-185

22. Bohnet M, Augustin W (1993) Effect of surface roughness and pHvalue on fouling behaviour of heat exchangers. In: Lee JS, Chung $\mathrm{SH}, \mathrm{Kim} \mathrm{KH}$ (eds) Transport phenomena in thermal engineering. Begell House, New York, pp 884-889

23. Crittenden BD, Alderman NJ (1992) Mechanisms by which fouling can increase overall heat transfer coefficients. Heat Transfer Eng $13: 32-38$
24. Nunner W (1956) Wärmeübergang und Druckabfall in rauen Rohren. VDI Forschungsheft 455, VDI-Verlag, Düsseldorf

25. Burck E (1969) Der Einfluss der Prandtlzahl auf den Wärmeübergang und Druckverlust künstlich aufgerauter Strömungskanäle. Heat Mass Transf 2:87-98

26. Hughmark GA (1975) Heat, mass, and momentum transport with turbulent flow in smooth and rough pipes. AICHE J 21:1033-1035

27. Ceylan K, Kelbaliyev G (2003) The roughness effects on friction and heat transfer in the fully developed turbulent flow in pipes. Appl Therm Eng 23:557-570

28. Gnielinski V (1995) Ein neues Berechnungsverfahren für die Wärmeübertragung im Übergangsbereich zwischen laminarer und turbulenter Rohrströmung. Forsch Ing-Wes 61:240-248

29. VDI-Wärmeatlas (2013) Chapter G1. Springer-Verlag, Berlin Heidelberg

30. Bohnet M (1987) Fouling of heat transfer surfaces. Chem Eng Technol 10:113-125

31. Brahim F (2003) Numerische Simulation des Kristallwachstums auf wärmeübertragenden Flächen. Dissertation, Technische Universität Braunschweig

32. Krischer O (1987) Die wissenschaftlichen Grundlagen der Trocknungstechnik. Springer-Verlag, Berlin Heidelberg

33. Brahim F, Augustin W, Bohnet M (2003) Numerical simulation of the fouling process. Int J Therm Sci 43:323-334

34. Comeaux RV (1978) Calcium sulphate anhydrite scaling of watercooled exchangers. Mater Performance 17:9-21

35. Hirsch H (1996) Scher- und Haftfestigkeit kristalliner Foulingschichten auf wärmeübertragenden Flächen. Dissertation, Technische Universität Braunschweig

Publisher's note Springer Nature remains neutral with regard to jurisdictional claims in published maps and institutional affiliations. 